197

$3 / 23 / 70$
1283

RFP-1449

March 11, 1970

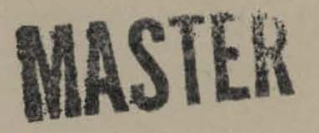

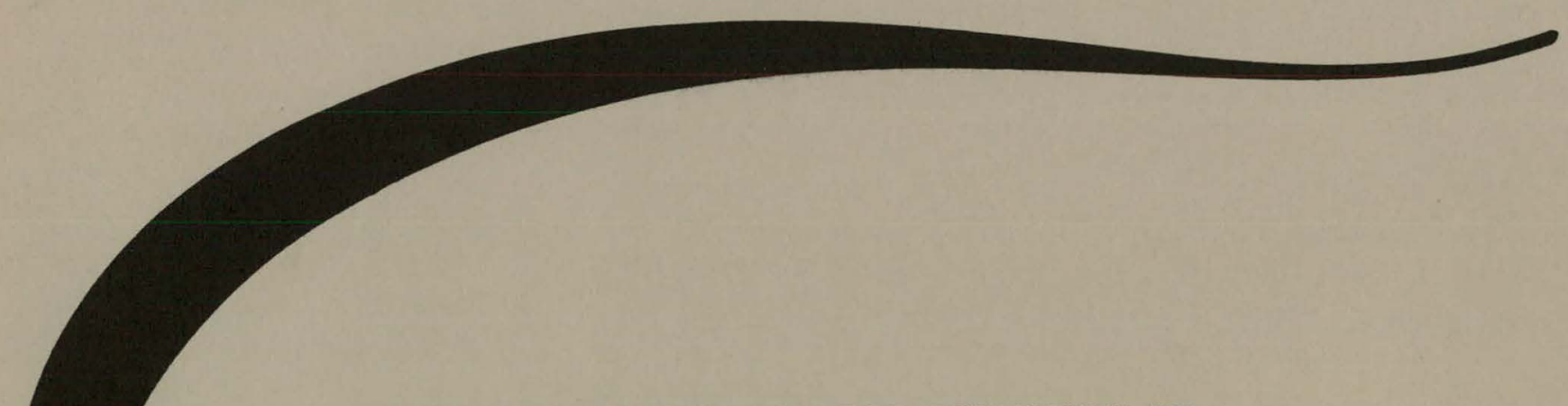

A FORTRAN IV PROGRAM FOR REDUCTION OF

SPECTROPHOTOMETRIC REACTION KINETICS DATA

George J. Werkema

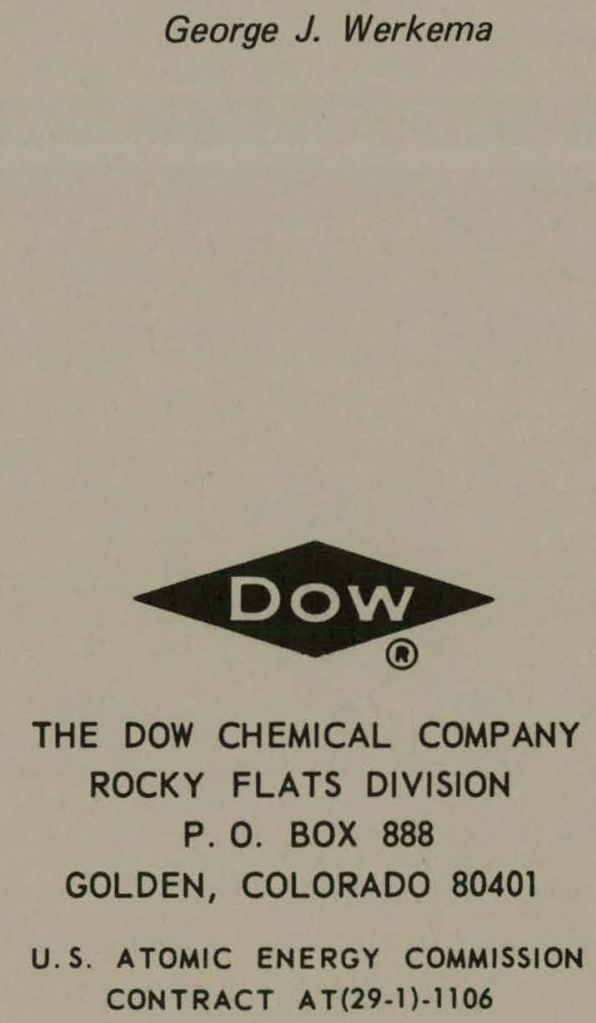




\section{DISCLAIMER}

This report was prepared as an account of work sponsored by an agency of the United States Government. Neither the United States Government nor any agency Thereof, nor any of their employees, makes any warranty, express or implied, or assumes any legal liability or responsibility for the accuracy, completeness, or usefulness of any information, apparatus, product, or process disclosed, or represents that its use would not infringe privately owned rights. Reference herein to any specific commercial product, process, or service by trade name, trademark, manufacturer, or otherwise does not necessarily constitute or imply its endorsement, recommendation, or favoring by the United States Government or any agency thereof. The views and opinions of authors expressed herein do not necessarily state or reflect those of the United States Government or any agency thereof. 


\section{DISCLAIMER}

Portions of this document may be illegible in electronic image products. Images are produced from the best available original document. 


\section{LEG A L NOTICE}

This report was prepared as an account of Government sponsored work. Neither the United States, nor the Atomic Energy Commission, nor any person acting on behalf of the Commission:

A. Makes any warranty or representation, expressed or implied, with respect to the accuracy, completeness, or usefulness of the information contained in this report, or that the use of any information, apparatus, method, or process disclosed in this report may not infringe privately owned rights; or

B. Assumes any liabilities with respect to the use of, or for damages resulting from the use of any information, apparatus, method, or process disclosed in this report.

As used in the above, "person acting on behalf of the Commission" includes any employee or contractor of the Commission, or employee of such contractor, to the extent that such employee or contractor of the Commission, or employee of such contractor prepares, disseminates, or provides access to, any information pursuant to his employment or contract with the Commission, or his employment with such contractor.

Printed in the United States of America

Available from

Clearinghouse for Federal Scientific and Technical Information

National Bureau of Standards, U. S. Department of Commerce

Springfield, Virginia 22151

Price: Printed Copy $\$ 3.00$; Microfiche $\$ 0.65$ 


\title{
A FORTRAN IV PROGRAM FOR REDUCTION OF SPECTROPHOTOMETRIC REACTION KINETICS DATA
}

\author{
George J. Werkema
}

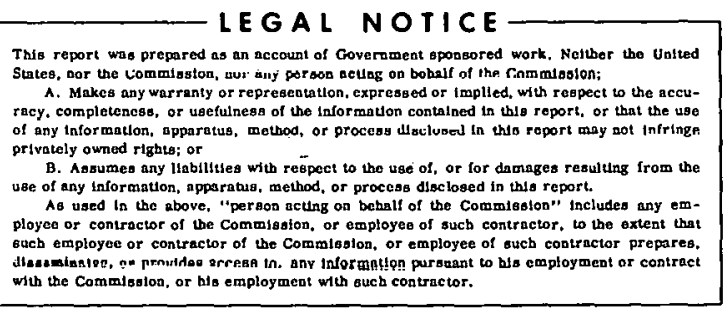

\author{
THE DOW CHEMICAL COMPANY \\ ROCKY FLATS DIVISION \\ P. O. BOX 888 \\ GOLDEN, COLORADO 80401 \\ Prepared under Contract AT(29-1)-1106 \\ for the \\ Albuquerque Operations Office \\ U. S. Atomic Energy Commission
}




\section{CONTENTS}

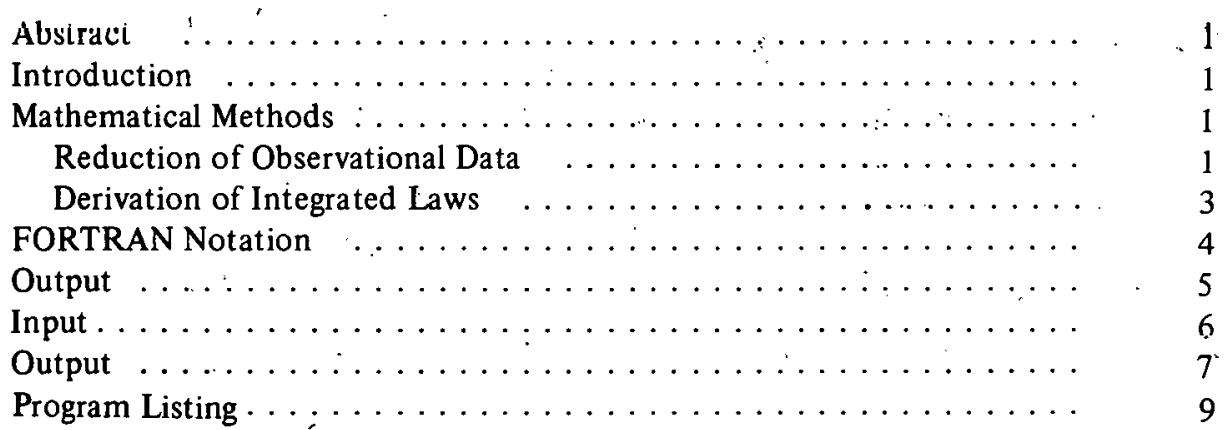




\title{
A FORTRAN IV PROGRAM FOR REDUCTION OF SPECTROPHOTOMETRIC REACTION KINETICS DATA
}

\author{
George J. Werkema
}

\begin{abstract}
This program is a modification of one written earlier ${ }^{1}$ for a small computer. The present version is written in E-level FORTRAN IV for the IBM 360-40G computer. The program reduces spectrophotometric absorbancy data to molar concentrations of reactants and products and, at the user's option, computes the rate constant time products $\left(k_{1} t, k_{2} t\right.$, and $\left.k_{3} t\right)$ using the integrated forms of first-, second-, and third-order rate laws.
\end{abstract}

\section{INTRODUCTION}

The reduction of spectrophotometric reaction kinetics data to molar concentrations of reactants and products is a tedious process. The ERLF program ${ }^{1}$ and the present modification, ERLF-2, were written to perform the appropriate reduction and to test the reaction rate dependency. ERLF-2 is written in E-level FORTRAN IV for the IBM $360-40 G$ computer.

The experiment for which ERLF-2 was written consists of observing the absorbance of visible or ultraviolet light at some discrete wavelength by one of the reaction constituents at several times during the course of a chemical reaction. Provision has been made in the program to correct for a minor interference from a chemical species whose concentration-rate-of-change is the negative of that for the species whose absorbance predominates at the obscrved wavelength. The matliematical derivation of the algorithm for these calculations is presented in the first paragraph of the next section.

The program has been written for chemical reactions of the type $A+B \rightleftharpoons C+D$. Species $B$ and $D$ are assumed to have zero absorbance at the observed wavelength. Species $A$ and $C$ have measurable absorbance at the observed wavelength with one species predominating by virtue of the relative magnitude of its molar extinction coefficient. That is, the molar extinction coefficient for species $\mathbf{A}$ at the observed wavelength must be much greater than that for species $C$ if the observed data correspond to a decreasing concentration of species $A$. Conversely, if the

\footnotetext{
${ }^{1}$ G. I. Werkema, "FORTRAN II Program for Rcduction of Spectrophutumetric Reaction Kinetics Data,"'RFP-629, Rocky Flats Division, The Dow Chemical Company, November 1965.
}

absorbancy increases during the course of the reaction, corresponding to an increase in the concentration of species $\mathrm{C}$, then the molar extinction coefficient for species $C$ at the observed wavelength must be much greater than that for species $A$. In general, these conditions are satisfied by standard spectrophotometric technique.

The program calculates the concentrations of species $A$, $B$, and $C$ for each datum and then proceeds to compute the corresponding rate constant time products $\left(k_{1} t, k_{2} t\right.$, and $k_{3} t$ ) using the integrated forms of first-, second- and third-order rate laws. Division of the time products by the elapsed time at each datum gives a number whose constancy, or lack of, throughout a reaction is an indication of the order of the reaction. Values of this number are also listed for each datum. Derivations of these algorithms are presented in the second paragraph of the next section.

\section{MATHEMATICAL METHODS}

We define a general stoichiometry factor, $P$, such that the stoichiometric equation may be written

$$
\mathrm{d}[\mathrm{A}]=\mathrm{p} \cdot \mathrm{d}[\mathrm{B}]
$$

This equation states that one gram-molecular-weight of $\mathbf{B}$ reacts stoichiometrically with $\mathbf{P}$ gram-molecular-weights of A. P need not be integral insofar as this program is concerned.

\section{Reduction of Observational Data}

In dilute solution, the absorbance of a species (A) in solution for a given wavelength of light $(\lambda)$ is equal to the product of its molar extinction coefficient $\left(\epsilon_{A}^{\lambda}\right)$ and its concentration, [A], that is

$$
\text { (Absorbance) })_{\mathrm{A}}^{\lambda}=\epsilon_{\mathrm{A}}^{\lambda}[\mathrm{A}] \text {. }
$$

The total observed absorbance $\left(\mathrm{Q}^{\lambda}\right)$ of a solution at a given wavelength is equal to the sum of contributions due to all absorbing species and may be expressed as

$$
Q^{\lambda}=\epsilon_{A}^{\lambda}[A]+\epsilon_{B}^{\lambda}[B]+\epsilon_{C}^{\lambda}[C]+\ldots
$$


This program has been written to accommodate two absorbing species, one of which is a reactant, the other a product. In the ensuing discussion it is assumed that $\mathrm{A}$ is a reactant, $\mathrm{C}$ is a product, the contribution to the absorbance at $\lambda 1$ is due primarily to $A$ and the contribution to the absorbance at $\lambda 2$ is due primarily to $C$. In addition, it is required that $-d[A]=d[C]$. The following paragraphs develop the relationships among these elements.

Absorbance at $\lambda 1$ : following the decrease of $[\mathrm{A}]$, with

$$
\epsilon_{\mathrm{A}}^{\lambda l}>\epsilon_{\mathrm{C}}^{\lambda l}
$$

The absorbance at $\lambda 1$ is equal to the sum of absorbances of the individual species present, that is, species $A$ and $C$. Thus we have

$$
\alpha^{\lambda 1}=\epsilon_{\mathrm{A}}^{\lambda 1}[\mathrm{~A}]+\epsilon_{\mathrm{C}}^{\lambda 1}[\dot{C}]
$$

with the contribution due to A being much larger. The amount of product $C,[C]$, present is equal to the sum of the amount initially present plus that which was produced at the expense of $\mathbf{A}$ during the reaction, that is

$$
[\mathrm{C}]=[\mathrm{C}]_{0}+\left\{[\mathrm{A}]_{0}-[\mathrm{A}]\right\}
$$

Equation (5) is valid only if $-d[A]=d[C]$.

Substituting (5) in (4) gives

$$
Q^{\lambda 1}=\epsilon_{A}^{\lambda 1}[A]+\epsilon_{C}^{\lambda 1}[C]_{0}+\epsilon_{C}^{\lambda 1}\left\{[A]_{0}-[A]\right\}
$$

Now let $\Theta^{\lambda 1}=Q^{\lambda 1} \cdot \epsilon_{C}^{\lambda l}[C]_{0}$.

$\theta^{\lambda 1}$ is, by this formulation, equal to the observed absorb. ance at $\lambda 1$ minus the absorbance due to any product $C$ which was present at zero time. Upon substitution of (7), (6) becomes

$$
\Theta^{\lambda 1}=\epsilon_{\mathrm{A}}^{\lambda 1}[\mathrm{~A}]+\epsilon_{\mathrm{C}}^{\lambda 1}[\mathrm{~A}]_{0} \cdot \epsilon_{\mathrm{C}}^{\lambda 1}[\mathrm{~A}]
$$

Rearranging (8) by solving for $[A]$ gives

$$
[\mathrm{A}]=\frac{\Theta^{\lambda 1} \cdot \epsilon_{\mathrm{C}}^{\lambda 1^{1}}[\mathrm{~A}]_{0}}{\epsilon_{\mathbf{A}}^{\lambda 1} \cdot \epsilon_{\mathrm{C}}^{\lambda 1}}
$$

Equation (9) is the programmed formula. The concentration of reactant $B,[B]$, is determined by the stoichiometric relationship of Equation (1). Note that in Equation (7) the correction to be applied must derive from some independent source. Usually, the most convenient way to do this is to extrapolate the absorbance at $\lambda 2$ to zero time, which mainly is due to [C]. The ratio of the extinction coefficients for $\mathrm{C}$ at $\lambda \mathrm{l}$ and $\lambda 2$ is the scale factor necessary to compute the correction. That is,

$$
\epsilon_{\mathrm{C}}^{\lambda 1}[\mathrm{C}]_{0}=\frac{\alpha_{\text {initial }}^{\lambda 2} \cdot \epsilon_{\mathrm{C}}^{\lambda 1}}{\epsilon_{\mathrm{C}}^{\lambda 2}}
$$

Absorbance at $\lambda 2$ : following the increase of $[\mathrm{C}]$, with

$$
\epsilon_{\mathrm{C}}^{\lambda 2}>\epsilon_{\mathrm{A}}^{\lambda 2}
$$

The absorbance at $\lambda 2$ is equal to the sum of absorbances of the individual species present, $A$ and $C$. Using the formulation of Equation (4), we have the following expression:

$$
Q^{\lambda 2}=\epsilon_{\mathrm{A}}^{\lambda 2}[\mathrm{~A}]+\epsilon_{\mathrm{C}}^{\lambda 2}[\mathrm{C}]_{\mathrm{T}},
$$

with the contribution due to $\mathrm{C}$ being much larger. $[\mathrm{C}]_{\mathrm{T}}$ is the total amount of product $\mathrm{C}$ present.

$$
[\mathrm{C}]_{\mathrm{T}}=[\mathrm{C}]_{0}+[\mathrm{C}]
$$

where $[\mathrm{C}]$ is the amount of product $\mathrm{C}$ which has been produced at the expense of $\mathrm{A}$ during the studied portion of the reaction, that is,

$$
[\mathrm{C}]=[\mathrm{A}]_{0} \cdot[\mathrm{A}]
$$

Let us rewrite $(12 b)$ to obtain

$$
[A]=[A]_{0}-[C]
$$

Upon substituting (12a) and (12c) in (11) we obtain

$$
\mathrm{Q}^{\lambda 2}=\epsilon_{\mathrm{A}}^{\lambda 2}[\mathrm{~A}]_{0}-\epsilon_{\mathrm{A}}^{\lambda 2}[\mathrm{C}]+\epsilon_{\mathrm{C}}^{\lambda 2}[\mathrm{C}]_{0}+\epsilon_{\mathrm{C}}^{\lambda 2}[\mathrm{C}]
$$

Now let

$$
e^{\lambda 2} \equiv Q^{\lambda 2} \cdot \epsilon_{C}^{\lambda 2}[\Gamma]_{0}
$$

Then

$$
\Theta^{\lambda 2}=\epsilon_{A}^{\lambda 2}[A]_{0}+\left(\epsilon_{C}^{\lambda 2} \cdot \epsilon_{A}^{\lambda 2}\right) \cdot[C] .
$$

Rearranging (15) by solving for [C] gives

$$
[\mathrm{C}]=\frac{\Theta^{\lambda 2}-\epsilon_{\mathrm{A}}^{\lambda 2}[\mathrm{~A}]_{0}}{\epsilon_{\mathrm{C}}^{\lambda 2}-\epsilon_{\mathrm{A}}^{\lambda 2}}
$$


Equation (16) is the programmed formula and is in the same form as Equation (9). Note that all dependence on the variability of $[A]$ has been removed. The quantity $\epsilon_{\mathrm{C}}^{\lambda 2}[\mathrm{C}]_{0}$ is the measured or extrapolated absorbancy due to the species $\mathrm{C}$ at zero time, which is, exactly $\alpha_{\text {initial }}^{\lambda 2}-\epsilon_{A}^{\lambda 2}[A]_{0}$, barring other interferences, the program determines whether to usc Equation (9) or Equation (16) by comparing the relative magnitudes of $\epsilon_{\mathrm{A}}^{\lambda n}$ and $\epsilon_{\mathrm{C}}^{\lambda \mathrm{n}}$. If $\epsilon_{\mathrm{A}}^{\lambda \mathrm{n}}>\epsilon_{\mathrm{C}}^{\lambda \mathrm{n}}$, Equation (9) is used; otherwise, the program chooses Equation (16). The condition $\epsilon_{\mathrm{A}}^{\lambda n}=\epsilon_{\mathrm{C}}^{\lambda n}$ is regarded as an error and the job is terminated.

\section{Derivation of Integrated Rate Laws}

First-Order Rate Law: The subprogram has been written for the special case in which the reaction rate is firstorder in reactant $B$, that is

$$
\frac{-d[A]}{d t}=k_{1} \cdot[B]
$$

in which $k_{1}$ is the first-order rate constant. The integrated form of this first-order rate equation is:

$$
\mathrm{k}_{1} \mathrm{t}=\mathrm{P} \cdot \ln \left(\frac{\mathrm{CB}]_{0}}{[\mathrm{~B}]}\right)
$$

where $[\mathrm{B}]=$ concentration of component $\mathrm{B}$ at any time in moles/liter, $[B]_{0}=$ initial concentration of component $B$ in moles/liter and $\mathbf{P}=$ stoichiometry factor.

Second-Order:Rate Law: The subprogram has been written for the special case in which the reaction is first-order in each reactant $A^{\prime}$ and $B$, that is

$$
\frac{-d[A]}{d t}=k_{2}[A] \cdot[B] \text {, }
$$

in which $k_{2}$ is the second-order rate constant. The integrated form of this second-order rate equation is

$$
\mathrm{k}_{2} \mathrm{t}=\frac{\mathrm{P}}{\mathrm{P} \cdot[\mathrm{B}]_{0} \cdot[\mathrm{A}]_{0}} \ln \frac{[\mathrm{A}]_{0} \cdot[\mathrm{B}]}{[\mathrm{B}]_{0} \cdot[\mathrm{A}]}
$$

where $[\mathrm{A}]=$ concentration of component $\mathrm{A}$ at any time, in moles/liter, $[A]_{0}=$ initial concentration of component $A$, in moles/liter and similarly for $[\mathrm{B}]$ and $[\mathrm{B}]_{0}$.

Third-Order Rate Law: The subprogram has been written for the special case in which the reaction rate is second-order in component $A$ and firstorder in component $B$, that is

$$
\frac{d[A]}{d t}=k_{3}[A]^{2}:[B],
$$

in which $k_{3}$ is the third-order rate constant. The integrated form of this third-order rate equation is

$$
\begin{aligned}
\mathrm{k}_{3} \mathrm{t}=\frac{\mathrm{P}}{\mathrm{P} \cdot[\mathrm{B}]_{0} \cdot[\mathrm{A}]_{0}}\left(\frac{1}{[\mathrm{~A}]}\right. & \left.-\frac{1}{[\mathrm{~A}]_{0}}\right) \\
& +\frac{\mathrm{P}}{\left(\mathrm{P} \cdot[\mathrm{B}]_{0} \cdot[\mathrm{A}]_{0}\right)^{2}} \ln \frac{[\mathrm{B}]_{0}[\mathrm{~A}]}{[\mathrm{A}]_{0}[\mathrm{~B}]},
\end{aligned}
$$

With the symbolic significances as before.

The program user may select any or all of the integrated rate law calculation routines. At least one must be specified in order to obtain printed output. The routines are selected by means of three control characters, L1, L2, and $\mathrm{L3}$, whose control functions are tabulated as follows:

If L1: $\quad=0$, do not calculate first-order rate constant; go on to test L2:

$>0$, compute and output reduced data and first order rate constants, then test L2.

If L2: $=0$, do not calculate second-order rate constants; go on to test L3;

$>0$, compute and output reduced data and second-order rate constants, then test L3.

If L3: $=0$, do not calculate third-order rate constants; go on to termination routine;

$>0$, compute and output reduced data and third-order rate constants, then go to termination routine. 
RFP-1449

\section{FORTRAN NOTATION}

The mathematical symbols used in the previous discussion are represented in the FORTRAN source program by the labels indicated as follows:

\section{Mathematical Symbol}

$[\mathrm{A}]_{0}$

$[\mathrm{B}]_{0}^{\circ}$

$[\mathrm{C}]_{0}$

[A]

[B]

[C]

$P$.

$\epsilon_{\mathrm{A}}^{\lambda \mathrm{n}}$

$\epsilon_{\mathrm{C}}^{\lambda n}$

\section{FORTRAN Label}

AO

BO

$\mathrm{CO}$

Y(I)

BT(I)

CT(I)

$P$

E3

E4
Mathematical Symbol

$\alpha^{\lambda_{n}}$

$\Theta \lambda \mathrm{n}$

$\mathrm{t}$

$\mathrm{k}_{1}$

$\dot{k}_{2}$

$\mathrm{k}_{3}$

$k_{1} l$

$k_{2} t$

$\mathrm{k}_{3} \mathrm{t}$

L1, L2, L3
FORTRAN Label

ABNS(I)

BRACK

X(I)

C1

$\mathrm{C} 2$

C3

C1T

C2T

C3T

L1, L2, L3

\section{INPUT}

\section{Card Column Format - Label \\ 5-8 I4 . NJOB Number of experimental data sets to be processed sequentially}

$2 \quad 5-8 \quad$ I4 . NRUN Run number, for experiment identification

$9.12 \quad 14 \quad$ NDP Number of data points recorded in the experiment

13:80 17A4 TITLE Alphanumeric information

$\begin{array}{lll}3 & 10 \quad 11\end{array}$

L1

First-order control character .

$11 \quad$ I1

L2

Second-order control character

$12 \quad 11 \quad$ L3 $\quad$ Third-order control character

13.20 F8.6 AO Initial concentration of species $\mathbf{A}$
$21.28 \quad$ F8.6 BO

$29.36 \quad$ F8.6

$37-44$

F8.6

$\mathbf{P}$

Stoichiometry factor $(\mathrm{d}[\mathrm{A}]=\mathbf{P d}[\mathrm{B}])$

45-52 F8.3 E3 $\quad$ Molar extinction coefficient of species A

53-60 F8.3 E4 $\quad$ Molar extinction coefficient of . species $\mathrm{C}$

$\begin{array}{lllll}4 & 13-20 & \text { F8.2 } & \mathrm{X}(\mathrm{I}) \quad \text { Time }\end{array}$

21.28 F8.3 ABNS(I) Absorbance 


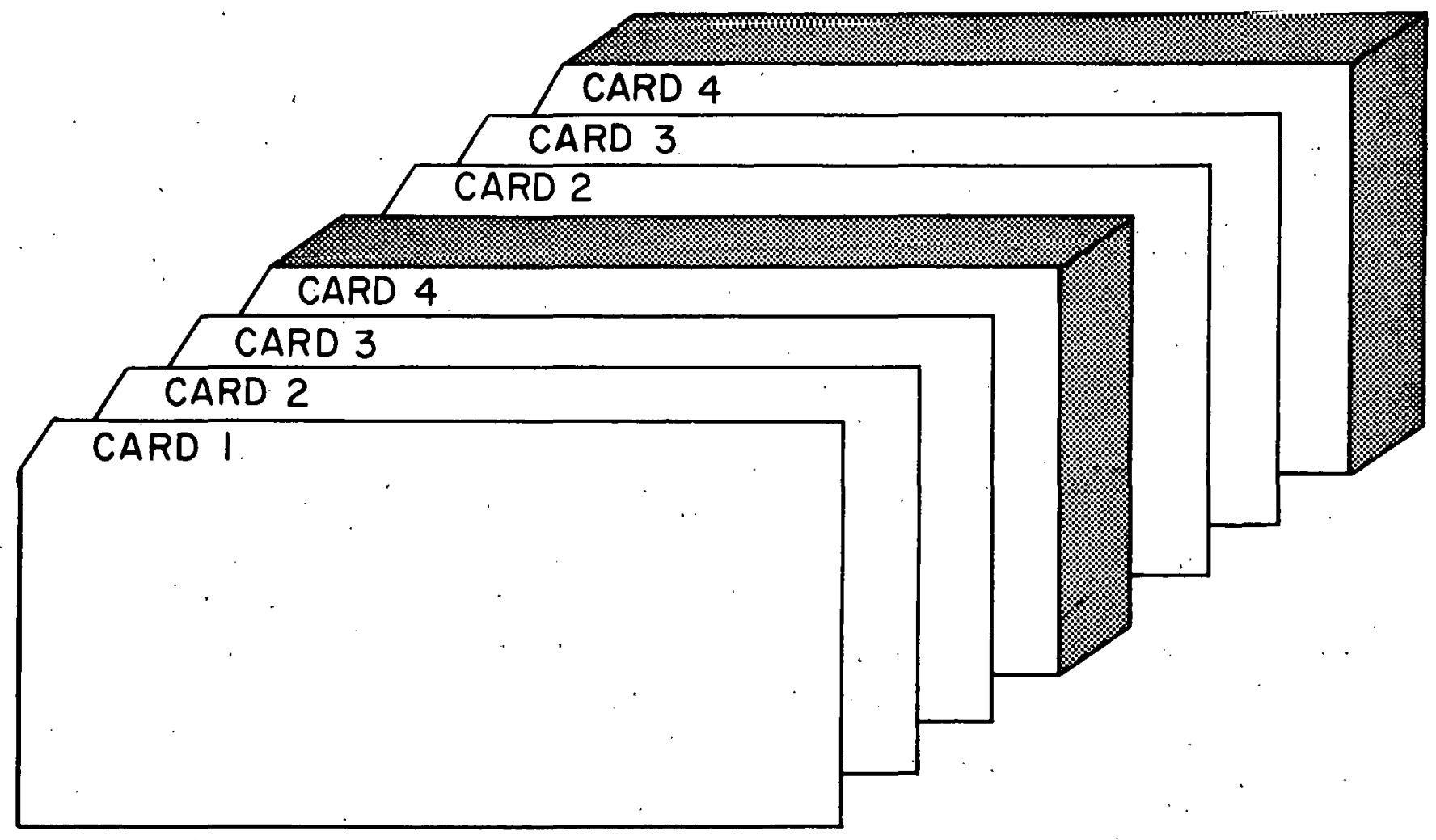

Figure 1. Data Deck.

Preparc one card 1 for each computer jub. One each of cards 2 and 3 are needed for each experimental run. Card 4 is a data point card and one is needed for each absorbance reading. Figure 1 shows a schematic of a deck make-up for a computer job which will process absorbance readings from two experimental runs.

\section{OUTPUT}

For each of the integraled reaction rate law calculations that is selected, one table is listed on the printer. The tables are arranged with the following format: line 1 is the "TITLE," reproduced verbatim from the information on data card 2; line 2 is self explanatory and contains the input constants NRUN, AO, BO, and $\mathrm{CO}$; the column headings for the result table are, left to right, T, X, A, B, C, Kl, KlT. T is time; $\mathrm{X}$ is the number of gram-molecular-weights of species $\mathrm{B}$ reacted $\left(=[B]_{0}-[B]\right) ; A, B$, and $C$ are the numbers of gram-molecular-weights of species $A, B$, and $C$ respectively, present in the reaction mixture; $\mathrm{K} l$, where $l=1,2$, or 3 depending on the order of the integrated law calculation, is the computed' rate constant time product divided by the time datum; $\mathrm{K} l \mathrm{~T}$, with $l$ as defirted before, is the computed rate constant time product. These results are computed for each absorbance measurement. 
SAMPLE INPUT

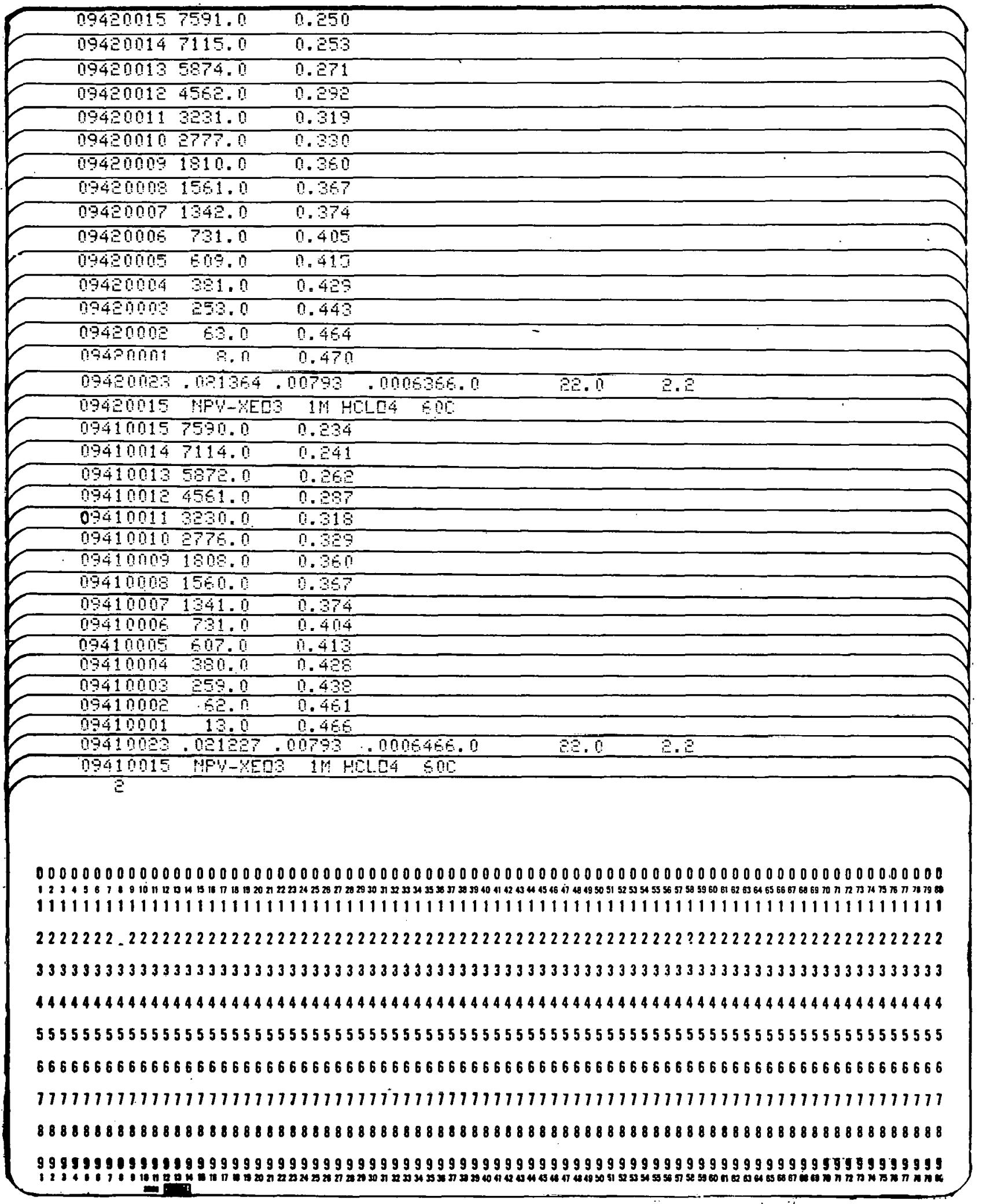


RFP-1449

SAMPLE OUTPUT

NPV-X்EO3 1 M HCLOH $60 \mathrm{C}$

RUN NO. $941 \quad A O=0.021227 \quad B O=0.007930 \quad C O=0.000646$

$\begin{array}{ccc}T & x & A \\ 13.00 & 0.000020 & 0.021105 \\ 52.00 & 0.000062 & 0.020853 \\ 259.00 & 0.000256 & 0.019691 \\ 380.00 & 0.000340 & 0.019186 \\ 607.00 & 0.000466 & 0.018428 \\ 731.00 & 0.000542 & 0.017974 \\ 1341.00 & 0.000795 & 0.016459 \\ 1560.00 & 0.000854 & 0.016105 \\ 1808.00 & 0.000913 & 0.015751 \\ 2776.00 & 0.001174 & 0.014186 \\ 3730.00 & 0.001265 & 0.013630 \\ 4561.00 & 0.001527 & 0.012065 \\ 5872.00 & 0.001738 & 0.010802 \\ 7114.00 & 0.001914 & 0.009741 \\ 7590.00 & 0.001973 & 0.009388\end{array}$

3

C. 007910

0.007868

0.007674

0.007590

0.007464

0.007388

0.007135

0.007076

0.007017

0.006756

0.006664

0.006403

c. 006192

c. 006016

0.005957 . $c$

0.000768

0.001020

0.002182

0.002687

0.003445

0.003899

0.005414

0.005768

0.006122

0.007687

0.008243

0.099808

0.011071

0.012132

0.012485
$\mathrm{K} 2$

0.055964

0.036346

0.037184

0.034304

0.030294

0.029756

0.025267

0.023679

0.022173

0.019920

0.018963

0.017526

0.016604

0.016086

0.015891
K2T

0.727527

2. 253483

9.630732

1. 3.035463

18.388367

21.751816

33.883621

36.939621

40.089523

55.2 .97745

61.251801

79.937775

97.498169

11.4 .434326

120.609833

NPV $-X E O 3 \quad 1 M \quad H C I O 4 \quad 60 C$

RUN NO. $941 A 0=0.021227 \quad B O=0.007930 \quad 0.0=0.000646$

$\begin{array}{rcccc}T & X & A & B & C \\ 13.00 & 0.000027 & 0.021105 & 0.007910 & 0.000768 \\ 52.00 & 0.000062 & 0.020853 & 0.007868 & 0.001020 \\ 259.00 & 0.000256 & 0.019691 & 0.007674 & 0.002182 \\ 380.00 & 0.000340 & 0.019186 & 0.007590 & 0.022687 \\ 607.00 & 0.070466 & 0.018428 & 0.007464 & 0.003445 \\ 731.00 & 0.00054 ? & 0.017974 & 0.007388 & 0.003899 \\ 1341.00 & 0.000795 & 0.016459 & 0.007135 & 0.005414 \\ 1560.00 & 0.000854 & 0.016105 & 0.007076 & 0.005768 \\ 1808.00 & 0.000913 & 0.015751 & 0.007017 & 0.006122 \\ 2776.00 & 0.001174 & 0.014186 & 0.006756 & 0.007687 \\ 3230.00 & 0.001266 & 0.013630 & 0.006664 & 0.008243 \\ 4561.00 & 0.001527 & 0.012065 & 0.006403 & 0.009308 \\ 5872.00 & 0.001739 & 0.010802 & 0.006192 & 0.011071 \\ 7114.00 & 0.061914 & 0.009741 & 0.006016 & 0.012132 \\ 7590.00 & 0.001973 & 0.009388 & 0.005957 & 0.012485\end{array}$

K 3

$2.644715 \quad 34.381302$

$1.727763 \quad 107.121353$

1.819657

1.701234

1.534090

1.5266887

1.3585251821 .783203

1.2881332009 .487305

$1.220830 \quad 2207.260986$

$1.161908 \quad 3225.457031$

1.1311743653 .694580

1.1208795112 .332 .031

1.132 .8066651 .835937

$1.167276 \quad 8304.007812$

1.1791638949 .847656 
RFP-1449

SAMPLE OUTPUT (Continued)

NPV-XEO3 $1 M$ HCLO4 $60 \mathrm{C}$

RUN NO. $942 A O=0.021364$ BO $=0.007930 \quad C O=0.000636$

$\begin{array}{rcccccc}T & \text { X } & \text { A } & \text { K } & \text { C } & \text { K2T } \\ \text { B.00 } & 0.009012 & 0.021293 & 0.007918 & 0.000707 & 0.052526 & 0.420211 \\ 53.00 & 0.000062 & 0.020990 & 0.007868 & 0.001010 & 0.035497 & 2.236298 \\ 253.00 & 0.000239 & 0.019929 & 0.007691 & 0.002071 & 0.035188 & 8.902465 \\ 381.00 & 0.000357 & 0.019222 & 0.007573 & 0.002778 & 0.035790 & 13.635991 \\ 609.00 & 0.000475 & 0.018515 & 0.007455 & 0.003485 & 0.030582 & 18.624161 \\ 731.00 & 0.000559 & 0.018010 & 0.007371 & 0.003990 & 0.030581 & 22.354950 \\ 1342.00 & 0.000820 & 0.016444 & 0.007110 & 0.005556 & 0.026021 & 34.920303 \\ 1561.00 & 0.000879 & 0.016041 & 0.007051 & 0.005909 & 0.024337 & 37.989716 \\ 1810.00 & 0.000938 & 0.015737 & 0.006992 & 0.006263 & 0.022737 & 41.153641 \\ 2777.00 & 0.001190 & 0.014222 & 0.006740 & 0.007778 & 0.020131 & 55.904068 \\ 3231.00 & 0.001283 & 0.013667 & 0.006647 & 0.008333 & 0.019145 & 61.857574 \\ 4562.00 & 0.001510 & 0.012303 & 0.006420 & 0.009697 & 0.017087 & 77.952606 \\ 5874.00 & 0.001687 & 0.011242 & 0.006243 & 0.010758 & 0.015695 & 92.195145 \\ 7115.00 & 0.001838 & 0.010333 & 0.006092 & 0.011667 & 0.014880 & 105.870117 \\ 7591.00 & 0.001864 & 0.010182 & 0.006066 & 0.011818 & 0.014267 & 108.300003\end{array}$

NPV-XEO3 IM HCLO4 6OC

RUN NO. $942 A 0=0.021364 \quad B O=0.007930 \quad C 0=0.000636$

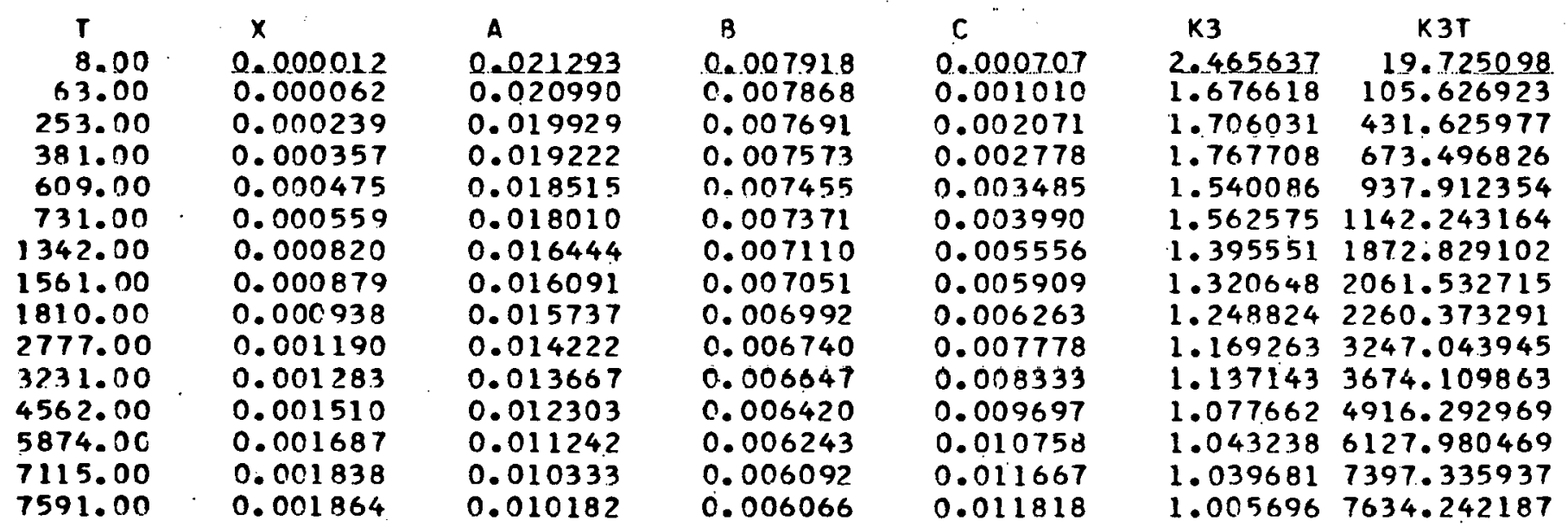


PROGRAM LISTING

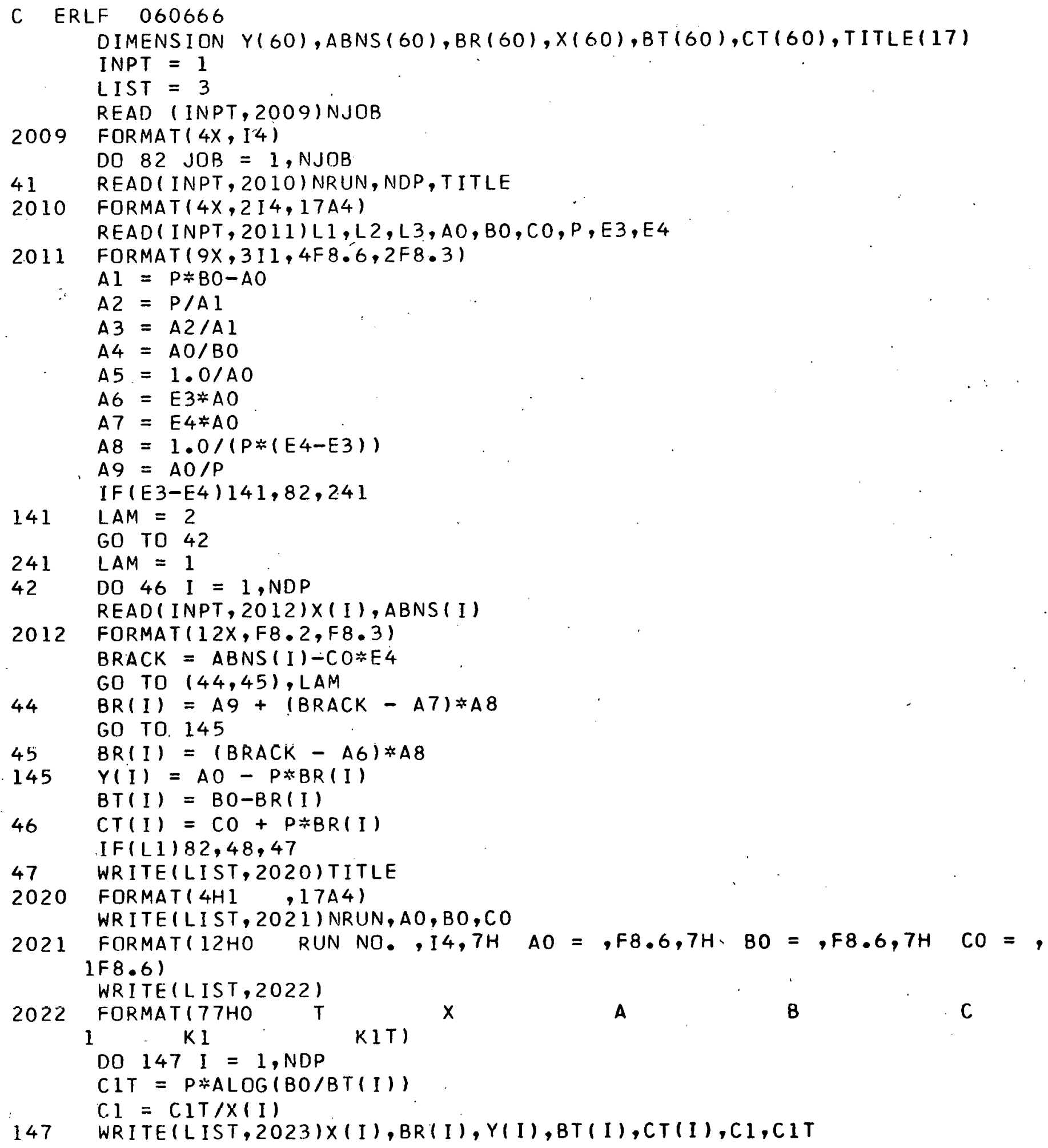




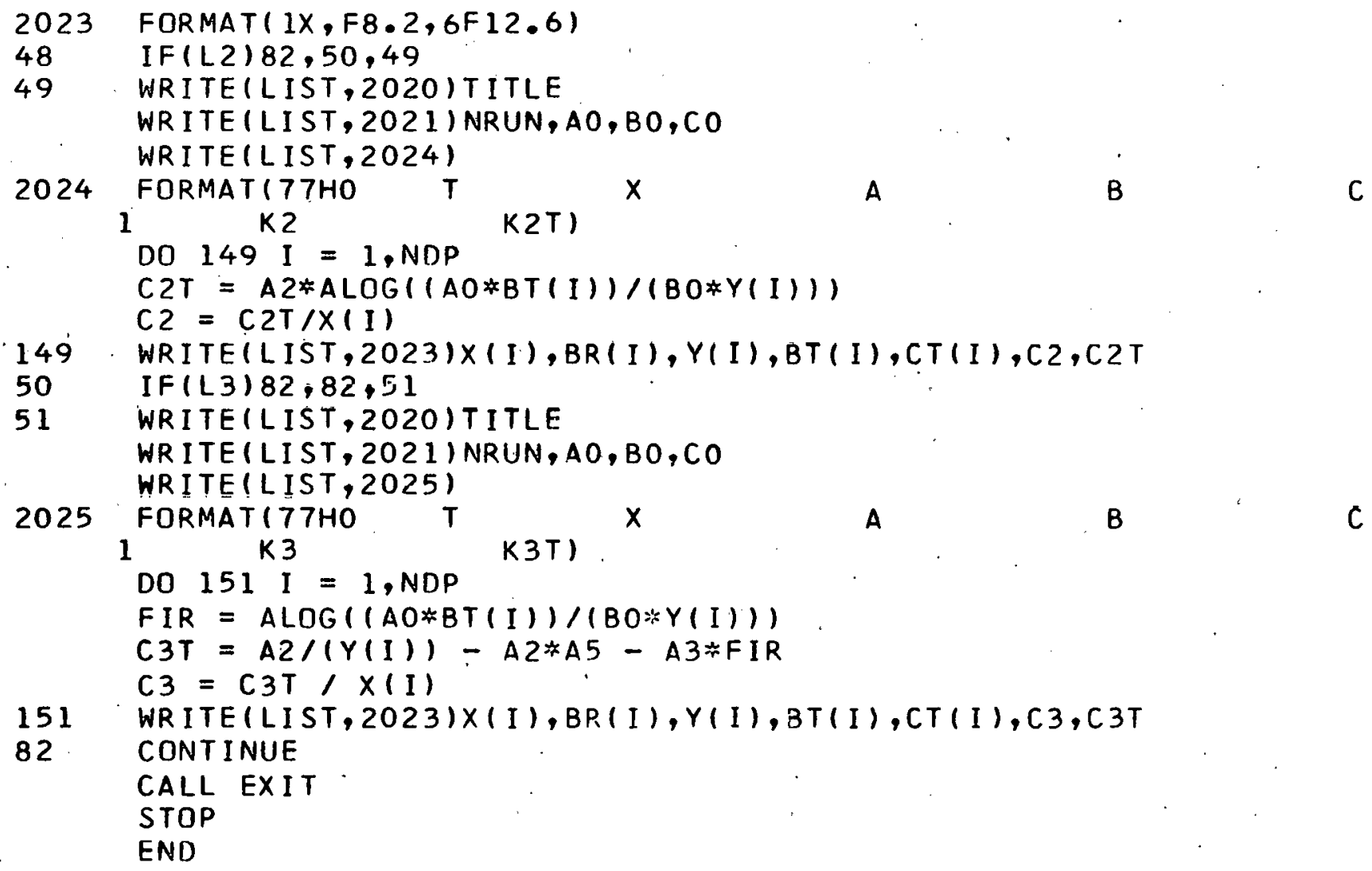

151 WRITE(LIST, 2023) X(I),BR(I),Y(I),BT(I),CT(I),C3,C3T

82. CONTINUE

CALL EXIT

STOP

END 